3. Griffix, J. L. and Allen, R. D., Exptl Cell Res. 20, 619 (1960).

4. Jennings, H. S., Contribution to the study of the behaviour of the lower organisms. Carnegie Inst., Washington, 1904.

5. Mast, S. O., J. Morphol. 41, 347 (1926).

6. Noland, L. E., J. Protozool. 4, 1 (1957).

7. Pantrin, C. F. A., J. marine biol. Ass. 13, 24 (1923).

8. Schaeffer, A. A., Amoeboid movement. Princeton University, New Jersey, 1920.

9. Shaffer, B. M., Adv. Morphogen. 2, 109 (1962).

10. - in Primitive Motile Systems in Cell Biology, p. 387. R. D. Allen and N. Kamiya (eds.) Academic Press, New York, 1963.

11. Wolpert, I. and O’Neill, C. H., Nature Lond. 196, 1261 (1962).

\title{
IMMUNOFLUORESCENT LOCALIZATION OF HUMAN PITUITARY LUTEINIZING HORMONE ${ }^{1}$
}

\author{
A. R. MIDGLEY, JR \\ Department of Pathology, The University of Michigan, Ann Arbor, Mich., U.S.A. \\ Received September 9, 1963
}

THE periodic acid-Schiff (PAS) reaction in basophiles of the anterior pituitary is thought to indicate the presence of thyroid stimulating hormone, follicle stimulating hormone, and luteinizing hormone $(\mathrm{LH})$ since these are glycoproteins. This contention has been supported by histochemical solubility studies [2], by cellular fractionation studies [5], and by cytologic changes in basophiles in various functional states $[4,11,12]$. Specific cellular localization similar to that accomplished for prolactin [3], growth hormone [6], and human chorionic gonadotropin (HCG) [7, 10], is lacking, however.

The rationale for the present study, the immunofluorescent localization of $\mathrm{LH}$, was suggested by the reported immunologic cross reaction between LH and HCG $[9,13]$. We had previously localized HCG to syncytiotrophoblastic cells [7] with an antiserum demonstrated to be specific for $\mathrm{HCG}$ and capable of neutralizing its biological activity [8].

Proof that our rabbit anti-HCG globulin preparation was capable of identifying LH was obtained in an agar-gel double diffusion study performed with the antibody globulins before and after labeling with fluorescein. Each globulin preparation gave a single precipitin band against $\mathrm{HCG}^{2}$ and purified human pituitary $\mathrm{LH}^{3}$ with a

1 This work was supported by Grant No. C-6115 from the United States Public Health Service.

2 The HCG employed in these experiments was generously supplied by Dr. A. C. Bratton, Jr., of Parke, Davis \& Co., Ann Arbor, Michigan, lot No. 580038 with a stated biological activity of 3388 I.U. per mg.

3 The author greatly appreciates the gift of purified human pituitary LH from Dr. Sanford $\mathrm{J}$. Steelman of the Merck Institute for Therapeutic Research, Rahway, N.J. The preparation was stated probably to contain traces of thyroid stimulating hormone, but less than 1 per cent follicle stimulating liormone. 


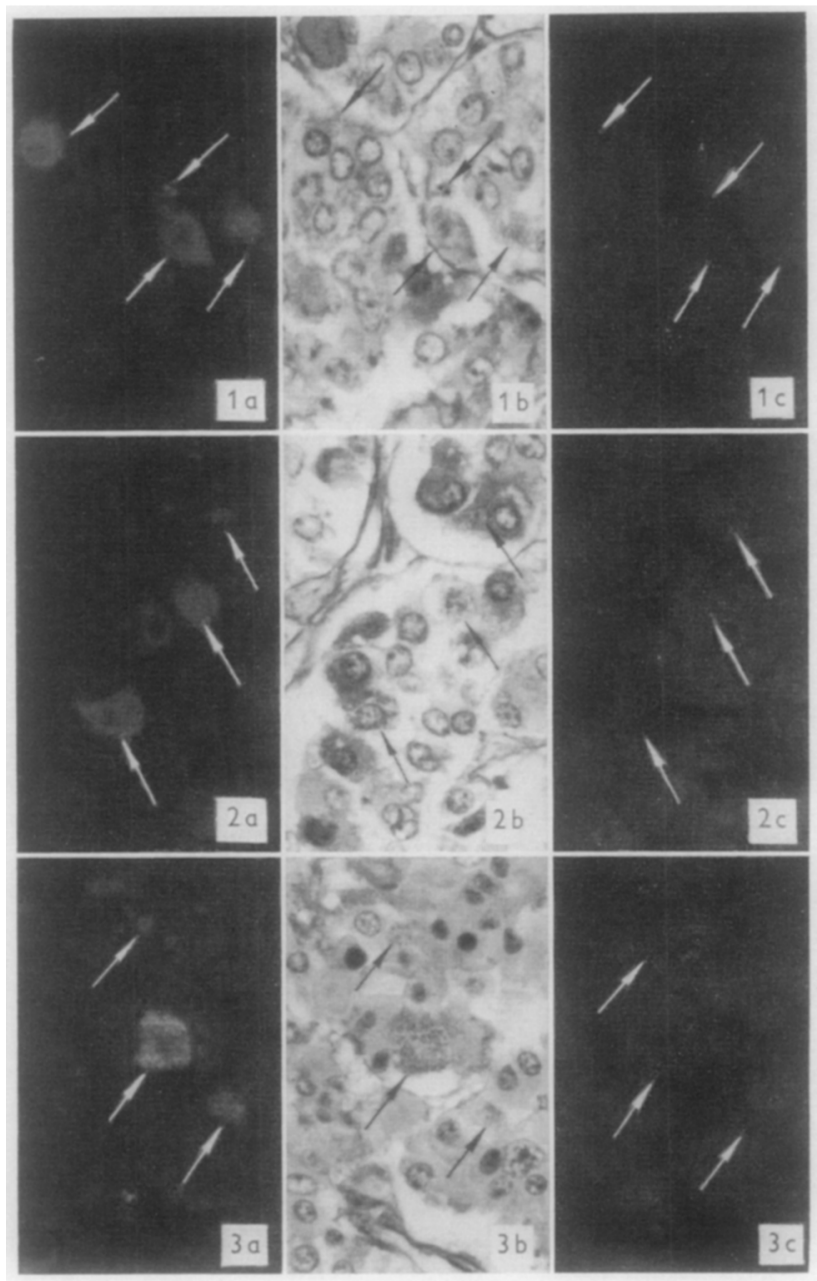

Fig. 1.-a, Section of anterior pituitary gland stained with fl-anti-HCG. Specific fluorescence, representing the localization of $\mathbf{L H}$, is confined to the cytoplasm of parenchymal cells (arrows). $\times 610$. $b$, Same section, same cells after staining by the PAS-hematoxylin procedure. LH is confined to lightly PAS positive granular cells. $\times 610$. $c$, Same area, but adjacent serial section serving as control and stained with fl-anti-HCG after absorption with LH. The lack of staining demonstrates the specificity of the staining in a (above). $\times 610$.

Fig. 2.-Same staining sequence as in Fig. 1. Note again that specific fluorescence is confined to lightly PAS positive granular cells. The more darkly PAS positive cells do not contain LH. Some of these darker cells, however, appear to contain a few droplets of LH (upper arrow).

Fig. 3.- Some of the more brightly fluorescent positive cells contain coars moderately dark PAS positive granules. $\times 610$. 
pattern of fusion. "Absorption" of $1 \mathrm{ml}$ of labeled or unlabeled antibody globulin by addition of either $1000 \mathrm{I}$.U. of $\mathrm{HCG}$ or $0.2 \mathrm{mg} \mathrm{LH}$ followed by incubation at $37^{\circ} \mathrm{C}$ for 30 min prior to gel diffusion abolished the precipitin band to both hormones. Furthermore, in contrast to normal rabbit globulin, $0.1 \mathrm{ml}$ of anti-HCG globulin, after incubation at $37^{\circ} \mathrm{C}$ for $30 \mathrm{~min}$, fully neutralized the ability of $30 \mu \mathrm{g}$ of $\mathrm{LH}$ to induce ovarian hyperemia in intact weanling rats. It was concluded that our anti-HCG globulin was capable of reacting specifically with biologically active LH.

Pituitary glands were obtained from twenty-six consecutive human necropsies, fixed in Bouin's fluid for $18 \mathrm{hr}$, washed in multiple changes of $0.02 M$ phosphate buffered saline, pH 7.0 (PBS), for 3 days at room temperature, and embedded in paraffin. Adjacent $4 \mu$ serial sections were stained [7] with (a) hematoxylin and eosin, (b) fluorescein labeled anti-HCG (fl-anti-HCG), (c) fl-anti-HCG absorbed with LH, and $(d)$ fl-anti-HCG absorbed with HCG. Coverslips were mounted with a mixture of nine parts glycerin to one part PBS. To determine whether cells containing LH were PAS positive, fluorescent positive cells were photographed, the coverslips removed, and the slides restained by the PAS procedure with a hematoxylin nuclear counterstain. The identical cells in the same sections were then re-located and photographed for the second time.

Positive cytoplasmic fluorescence, diffuse and stippled, was found in isolated and occasionally clustered parenchymal cells in sections from 25 of the 26 pituitary glands examined. In every case this specific fluorescence was absent in the adjacent serial control sections stained with the same conjugate after absorption with either LH or HCG. Furthermore, fl-anti-HCG did not stain non-pituitary control tissues. It was concluded, therefore, that the specific cytoplasmic fluorescence represented the localization of the immunologically reactive portion of LH.

The fluorescent-positive cells appeared to be distributed randomly throughout the anterior lobe. Occasionally, they appeared as brightly staining clusters comprising entire acini, a phenomenon most marked in the pars tuberalis and in cell nests in the posterior lobe of the pituitary gland. The positive cells were found to be sparsely and coarsely granulated, and lightly to moderately PAS positive (Figs. 1, 2, and 3). Most of the strongly PAS-positive cells did not stain with fl-anti-HCG (Figs. 1 and 2). Isolated brightly fluorescent droplets frequently were found in otherwise negative cells (Figs. 1 and 2). These intracytoplasmic droplets usually could be identified after restaining as dark PAS-positive structures. The distribution and histochemical reactions of these cells in functional states will be the subject of a separate communication.

Special note should be made of the method employed for fixation of LH. The present procedure was previously found to give the best immunofluorescent localization of HCG [10]. Formalin fixation appears to be necessary and should be done before embedding or freezing. Formalin may act by stabilizing LH-containing granules since formalin has been shown to prevent the solubilization of PAS reactive material in pituitary basophiles occasioned by lipid solvent fixatives [1]. If paraffin embedding is used, much brighter specific fluorescence results if the formalin is removed by thorough washing before cmbedding. Previously, using the same reagents, we were unable to localize LH in sections fixed in formalin and embedded directly.

Summary.-Luteinizing hormone was localized immunohistochemically to certain granular periodic acid-Schiff positive cells in the anterior lobe, in the pars tuberalis, 
and in the cell nests in the posterior lobe of the human pituitary gland. This study was performed with rabbit antiserum specific for human chorionic gonadotropin which was shown to cross react in gel diffusion analysis with purified human pituitary luteinizing hormone and to be capable of neutralizing its biological activity.

The author is pleased to acknowledge the technical assistance of Miss Ida Fai-Fong Fong.

\title{
REFERENCES
}

1. Bahn, R. C., Ross, G. T. and Schmit, R. W., J. Histochem. Cytol. 6, 387 (1958).

2. Bannnett, R. J., Lodman, $\Lambda$. J., Mgallaster, N. J. and Siperstein, E. R., Endocrinology $59,398(1956)$.

3. Emmart, E. W., Spicer, S. S. and Bates, R. W., J. Histochem. Cytol. 11, 365 (1963).

4. Halmi, N. S. and De Groote, J. W., J. Clin. Endocrinol. 21, 732 (1961).

5. Hymer, W. C. and McShan, W. H., J. Cell Biol. 17, 67 (1963).

6. Leznoff, A., Fishman, J., Goodfriend, L., McGarry, E., Beck, J. and Rose, B., Proc. Soc. Exptl Biol. Med. 104, 232 (1960).

7. Midgley, A. R., Jr. and Pierce, G. B., Jr., J. Exptl Med. 115, 289 (1962).

8. Midgley, A. R., Jr., Pierce, G. B., Jr. and Weigle, W. O., Proc. Soc. Exptl Biol. Med. 108, 85 (1961).

9. Moudgal, N. R. and LI, C. H., Nature 191, 192 (1961).

10. Pierce, G. B., Jr. and Midgley, A. R., Jr., Am. J. Pathol. 43, 153 (1963).

11. Purves, H. D. and Griesbach, W. E., Endocrinology 56, 374 (1955).

12. Swanson, H. E. and Ezrin, C., J. Clin. Endocrinol. 20, 952 (1960).

13. Wide, L., Roos, P. and Gemzell, C. A., Acta Endocrinol. 37, 445 (1961).

\section{TIME-COURSE OF DNA SYNTHESIS IN HUMAN LEUKOCYTE CULTURES}

\author{
A. M I CHALOWSK I \\ Institute of Oncology, Warsaw, Poland \\ Received September 20, 1963
}

THE widespread application of the short-term culture of human white blood cells to medical genetics and a more theoretical interest in the action of phytohaemagglutinin (PHA) on leukocytes in vitro justifies the need of a thorough investigation of the changes to which mature leukocytes are subject in the culture. The present communication is concerned with the rate of deoxyribonucleic acid (DNA) synthesis as a function of time in the population of human white blood cells cultured with the use of PHA according to a modification [3] of the original method of Moorhead et al. [8].

A healthy 33-year-old man served as a blood donor throughout this investigation. Several $10 \mathrm{ml}$ aliquots of blood were aspirated from the cubital vein into syringes containing $0.3 \mathrm{ml}$ of heparin Leo $(4 \mathrm{mg} / \mathrm{ml} 0.9$ per cent $\mathrm{NaCl}$ ) in each of 12 separate 